\title{
How do Vested Interests Maintain Outdated Policy? The Case of Food Marketing to New Zealand Children
}

\author{
Penny Field ${ }^{1}$ and Robin Gauld ${ }^{*}, 2$ \\ ${ }^{1}$ Department of Human Nutrition, University of Otago, PO Box 56, Dunedin 9054, New Zealand \\ ${ }^{2}$ Department of Preventive and Social Medicine, University of Otago, PO Box 913, Dunedin 9054, New Zealand
}

\begin{abstract}
This paper examines the role of powerful vested interest groups in determining public health nutrition policy. With childhood obesity now being classified as an epidemic, television food advertising to children is a relevant case study, which is reported on in this article. The study consisted of qualitative interviews with members of the New Zealand food advertising policy community and documentary analysis of relevant submissions to two government inquiries, websites and policy documents related to food advertising to children. The findings categorised the positions of three identifiable interest groups. Each group's use of evidence and other influence strategies was examined in relation to their impact on government policy. We found the food industry to be tightly coordinated in their influence activities, public relations, partnership agreements and the creation of scientific uncertainty. Non government organisations were less coordinated in their advocacy for regulation, relying heavily on the use of scientific evidence to support their position. As a result industry groups dominated the processes to produce a policy outcome where the government was not acting in its own best economic interest, in terms of reducing the longer-term costs of obesity, or that of the public. The evidence from this study supports international recommendations for new approaches to health policymaking. Government needs to lead a collaborative process between vested interest groups to ensure industry groups do not have the upper hand. Such approaches would enable policy with positive public health outcomes.
\end{abstract}

Keywords: Public health nutrition policy, vested interests, influence tactics, food advertising, children.

\section{INTRODUCTION}

Health professionals and epidemiologists are deeply concerned about the rising rates of childhood obesity, with some claiming that in the $21^{\text {st }}$ century children will have reduced life expectancy and may not outlive their parents [1]. Globally, over 42 million children under the age of five are estimated to be overweight. Close to 35 million of these children live in developing countries. All have an increased risk of morbidity, disability and premature death [2]. Meanwhile, across the developed world, policy to prevent obesity is in a state of flux. This is partly due to the role played by organised groups who are active in advocating for policy congruent with their interests. The activities of these groups are clearly evident in the analysis of childhood obesity prevention policy.

Food marketing to children is a controversial contributor to the obesogenic environment. The food industry argues food intake is a personal choice and policies designed to restrict food marketing reduce an individual's autonomy. Public health nutrition experts take a different position, that children need protection from marketing activities [3-6]. Their views are based on psychology research showing children are not able to discriminate the persuasive intent of advertisements and that advertised foods are of poor nutritional quality $\mathrm{On}$ issues where public health interests are in conflict with commercial interests, such as tobacco,

*Address correspondence to this author at the Department of Preventive and Social Medicine, University of Otago, PO Box 913, Dunedin 9054, New Zealand; Tel: 643479 8632; E-mail: robin.gauld@otago.ac.nz alcohol and food marketing to children, industry groups argue vigorously for self-regulatory policy with voluntary codes and complaint mechanisms [7-9]. Whilst these arguments often claim lower cost than government regulation and flexibility to adapt to new media, industry's underlying goal is self-determination.

In the twenty first century television is one of many ways children are exposed to persuasive food and drink marketing. Additionally, they are targeted by a range of non-broadcast media including social media and school based promotions, all of which are designed to build brand loyalty [10]. Children's purchase behaviour, diets and health are adversely influenced by the marketing of high fat, sugar and salt foods [11]. Television advertising has been the largest single medium for advertising to children $[11,12]$ although other media have an increasing presence as young peoples' access to technology increases and marketers exploit new media [13]. As television is more easily monitored than other media, the impact of policy is readily assessed.

Despite a growing body of international evidence highlighting the role food marketing plays in childhood obesity $[11,14,15]$, governments appear to struggle with developing and monitoring effective policy solutions. Both industry self-regulation and siloed health and media policy have proven to be, ineffective policy approaches [16]. Depending on how cogently industry has presented its views governments internationally have produced varied policies on television advertising to children. These range from complete bans as occurs in Sweden and Norway, to prohibitions in the United Kingdom on food and drink 
advertisements for less healthy food during children's viewing times [17], to total self regulation by the food and advertising industries in the United States and New Zealand [18]. In both these countries, industry funded institutions administer voluntary guidelines for the quantity and content of advertisements targeting children [8, 19]. The US and NZ also share the dubious record for being the two countries in the world where direct drug advertising to the public is permitted.

This paper seeks to explore the role of interest groups in maintaining policy approaches that serve them well. We use a case study approach to look critically at interest groups, their positions and how they exercise power in shaping policy outcomes. The case study offers insights into the real world of policymaking and the influence of interest groups on decision-making. Lewis [20] and others [9, 21, 22] use the construct of 'vested interests' to explain how powerful groups influence health policy. To examine the role of key players we have allocated vested interest groups into three broad categories: government policy makers, nongovernmental groups (NGOs), and industry groups. The field of Public Health Nutrition is easily characterized as a public policy domain with great complexity, interdependence and high stakes [23]. Challenges arise from the absence of immediate empirical measures of policy outcomes, the high interdependence of health with other policy domains and the dearth of well-developed theories and evidence linking health system inputs to outputs. It is in this milieu that these three groups of policy actors are working to assert their vested interests.

Following an examination of the positions of the three groups around policy development for food marketing to children in New Zealand, we critique the policy processes using the vested interests construct. We then compare the current policy outcomes against two meta policy frameworks; the International Obesity Task Force's policy recommendations [24] and the Ecological Public Health framework [16]. Both these emerging policy development approaches require discourses about wider issues. The World Health Organization (WHO) classifies the increasing prevalence of childhood obesity as one of the most serious public health challenges of the $21^{\text {st }}$ century [2]. Whilst some groups advocate for strong government leadership to protect public health through regulation [25], others are working strenuously to persuade governments that intervention is not necessary. At the intersection of these two policy drivers, childhood obesity as a serious public health problem and the actions of vested interest groups, two questions are generated: how do vested interest groups influence government policy and what are the implications for the obesity problem?

\section{METHODS}

In order to study the activities of the vested interest groups we undertook a case study on television food marketing to children in New Zealand. New Zealand is a small country of around four million people, with an easily identifiable, active policy community. In keeping with case study methodology [26], our case study examined activities that have influenced government decision making on food advertising since 2004. The case study explores the positions of each group, their advocacy activities and use of evidence. In line with the case study approach, which entails a combination of methods, qualitative interviews and documentary analyses were undertaken to capture the views of individuals and groups. By recording these different views, a source of explanations for wider policy determinants was generated [27]. Specifically, the case study drew on semi-structured interviews with eight senior members of the vested interest groups (see Table 1). We combined this with analysis of publically available and indexed media reports, internal government documents obtained under New Zealand's Official Information Act, publically available government select committee reports and NGO position statements. The University of Otago provided ethical approval. All interviews were recorded, transcribed and qualitatively analysed for themes relating to the position of the vested interest group and advocacy activities to advance their position.

Table 1. Vested Interest Group Interviewees

\begin{tabular}{|c|c|c|}
\hline Group & Number of Interviewees & Position Held \\
\hline \hline NGO & $\begin{array}{c}\text { Coalition Group } \\
\text { Representatives x 3 }\end{array}$ & Chair, CEO \\
\hline Food Industry & Self Regulatory Authority x 2 & CEO \\
\hline Policymakers & Senior Health Officials x 2 & $\begin{array}{c}\text { Senior Policy Analyst } \\
\text { Section Manager }\end{array}$ \\
\hline
\end{tabular}

\section{RESULTS}

We found three groups with distinct positions active in policy discussions on food advertising to children. The NGO group comprised several coalitions and larger NGOs that spoke on their own behalf in addition to their role as coalition members. By contrast, the food industry were organised as one coalition group with a strong contribution from the broadcast and media industries. The government policymakers were active in translating the findings of two consultation rounds into proposed legislation. The positions held by each group, their advocacy activities, use of evidence and their resulting influence on government policy is discussed below.

\section{Food Industry Group}

The Food Industry Group comprises food producers, wholesalers, retailers and marketers. In 2003, under a centreleft government, NGO groups were advocating for regulatory intervention to slow increasing rates of obesity. Two high profile seminars were held in 2003 to discuss policy options, with both events including contributions from Health Ministers and the food industry. In response to the NGO advocacy activity, a number of food industry and commercial trade associations organised themselves and formed the Food Industry Group [FIG] in 2004. This coalition group is constituted as a society, is member-funded and employs a Chief Executive. The four principal members are the New Zealand Food and Grocery Council, the Association of New Zealand Advertisers, the Communication Agencies Association of New Zealand and 
the New Zealand Television Broadcasters Council, now known as ThinkTV.

The stated mission of FIG is "to change the way the food industry thinks and acts on food choice, ingredients and promotion so it is in line with the [government] Healthy Eating, Healthy Action strategy" [28]. By aligning the goal of the FIG to the government's major obesity policy activity the food industry positioned them as working alongside government to manage the 'problem'. During 2003 and 2004 FIG members undertook concerted relationship building activities, primarily with government decision makers and selected academics [28]. In addition to a strong presence at the two seminars mentioned above, FIG members regularly met with senior Ministry of Health officials. Initially this relationship management activity led to the Food Industry Group signing a voluntary agreement with the Ministry of Health in September 2004, known as the Food Industry Accord. This commits FIG: "To do all that is possible to encourage all sectors of the food industry to create commercially successful products and services that will make a positive contribution to the health of New Zealanders" [29]. From 2005 to 2008 the 'Dialogue and Influence' meetings with the Ministry of Health were scheduled on a fortnightly basis [30]. Television and press media gave a high level of coverage to all these industry initiated activities from 2003 to 2010.

Members of the FIG used a 2006 government Health Select Committee Inquiry into Obesity and Type 2 Diabetes to continue to advocate for industry self regulation, encapsulated by the submission from the New Zealand Television Broadcasters' Council:

"An effective, socially responsible fabric of rules and regulations exists across all advertising with television being at the forefront of offering a socially responsible approach in New Zealand [based around Broadcasting Standards Authority and Advertising Standards Authority codes]... This framework works well. The NZTBC has seen no information that the incidence of obesity would be reduced through greater regulation" [s293, p4] [31].

Arguments based on individual choice, autonomy and education were used as justifications for this policy outcome:

"At the centre of the solution is the individual... Given the range and availability of food items on offer, the key is in giving people the knowledge and ability to make healthy choices. It comes down to teaching people the basic principles of how much they consume $v s$ how much they move " [31].

"We live in a democracy, not a dictatorship, and thus we cannot tell people that they cannot eat some foods but eat lots of others. We can only exhort. It is how well we exhort the consumption of healthy diets and living healthy lifestyles that will achieve the objectives of reducing obesity and the incidence of type 2 diabetes" [32].
All the industry submissions argued that there was insufficient evidence on effective obesity interventions and that more evidence was needed, as the FIG submission illustrates:

"Some people claim that even though we do not know enough about the causes of the problem, we must still act - as if panicking blindly will be more helpful than taking a moment to size up the situation. If we do not answer the questions above [about causes], then New Zealand runs the risk of attempting solutions which unnecessarily impact on all New Zealanders while being unlikely to make any significant impact on those who are obese [s157, p9]" [33].

The FIG asserted that their advocacy was evidence based and highly influential:

"The submissions presented by industry have provided in-depth, evidence based information that has made a major contribution to the debate" [34].

However, most of the evidence cited was either unpublished reports or from minor journals. In spite of this, the Select Committee recommended to Government that self regulation continue, with the FIG and Ministry of Health to be jointly given targets and timeframes for the "advertising, marketing and promotion of healthier diets, especially to children..." [35].

Advocacy by the food industry for self-regulation policy continued after the Health Select committee inquiry. In 2007/2008 Government policymakers proposed updated public health legislation in the Public Health Bill. This recommended a moderate level of government intervention for non-communicable diseases such as obesity. A formal Government - industry partnership was proposed, however, industry did not change their position on self regulation. Instead they attempted to strengthen their argument by adding a new human rights dimension to their case, as one Food Company's submission illustrates:

"powers to regulate were unnecessary, unreasonable and conflicted with the Bill of Rights. To introduce overt state coercion in the food choices of citizens is going one step too far" [36].

The New Zealand Retailers Association added the benefits of a collective industry approach:

"As a matter of principle we are totally supportive of industry working together to develop, foster and maintain voluntary self regulatory processes that achieve socially and economically desirable outcomes rather than having regulatory outcomes foisted upon industry by central Government" [37].

\section{Non Governmental Organisations (NGOs)}

The second identifiable group comprised NGOs, academic interest groups and professional associations. Compared to the Food Industry Group this grouping included a number of smaller organisations and individuals, 
and many had fewer financial resources. At the beginning of the case study (2006) three NGO coalitions existed, the Obesity Action Coalition, Agencies for Nutrition Action and the Chronic Disease Prevention Peak group. These coalitions represented the major nutrition NGO groups in NZ. However, there was a high level of overlap in membership: the National Heart Foundation and Diabetes NZ belonged to all three coalitions, the Cancer Society, Dieticians NZ and Te Hotu Manawa Maori [the indigenous branch of the National Heart Foundation] belonged to two coalitions. Through partnerships with academics these coalition groups overtly positioned themselves as the voice of scientific reason. Their collective position that obesity has wider environmental and social determinants was supported by extensive published evidence. International experience was used as the base for arguments that these wider determinants require government regulatory intervention.

NGO group submissions to the 2006 Health Select Committee inquiry on Obesity and Type 2 Diabetes framed their pro regulation arguments on strategies known to be effective. The National Heart Foundation's submission illustrates this position:

\begin{abstract}
"The government should consider obesity a normal response to an abnormal environment. Many of the determinants of obesity are structural and environmental and are outside the control of families/whanau and individuals. Therefore focusing interventions solely on educating people and trying to get them to 'pull themselves up by their boot straps ' ignores all that we know about what determines health and well being. Worse, it is an ineffective, naïve and futile approach that delays effective actions and widens ... disparities" [38].
\end{abstract}

In their submissions to the Inquiry and in the press, NGO coalition groups also argued that evidence of 'what works' overseas should be applied to New Zealand:

"...international experience showed that voluntary codes and self regulations did not bring about significant change for children" [39].

NGO group advocacy took the form of hosting and publicising seminars for academics and other members of the policy community, and commissioning and disseminating reports by academic researchers [40-42]. Around the time of these events 2006 - 2008, seminar keynote speakers and report authors enjoyed a high media presence, creating a short-term public profile for the NGO position.

Although the NZ Medical Association is not a member of the NGO coalitions, they were active in arguing the same pro regulation position from a research-led evidence base. The association adopted the position held by the wider international medical community that "some measures need to be taken to regulate the type of food advertising aimed at children" [43]. The influence of all the NGO groups was largely in the public domain through press releases, television and radio interviews. A high media profile enabled their arguments to be shared with the New Zealand public although this strategy did not appear to be coordinated between the NGO groups.

\section{Government Policy Makers}

The third identifiable group were policy makers employed by government departments to provide policy advice to elected officials. Unlike some other countries, notably Britain, the NZ Ministry of Health has retained jurisdiction over the issue of food advertising to children. Individual Ministry Policy makers are more difficult to identify as in the NZ context they are employees of an apolitical government service, and strictly speaking only the Chief Executive or the Minister produce policy statements. However, policy makers employed in government agencies are answerable to politicians who set clear expectations as a former New Zealand Minister of Health, Pete Hodgson, illustrated in his address to a 2006 Food industry conference:
"those of you sitting in this room, and the organisations you represent have the collective power to change New Zealand's food environment - what is available to buy, how it is priced and how we purchase it. There is a strong sense of urgency to make these changes in light of the obesity epidemic we are now facing" [44].

Some lobby groups were aware of officials and politicians holding differing views, as the spokesperson for one NGO group said:

“...the Ministry [officials] would be aligned with us and the public.... and we have the industry and politicians as our opposition" [45].

Health policy makers revealed their preference for a regulatory framework in the 2007 Public Health Bill. This draft legislation was released in the policy window following the presentation of the Obesity and Type 2 Diabetes Inquiry report and before the Government had produced their response [46]. The proposed regulatory framework had a short life, as the Health Committee considering the Public Health Bill did not support regulatory policy. The committee were persuaded that voluntary codes would be effective, on the condition that targets and timeframes were met. To appease the majority of submitters favouring regulation the Committee recommended the Minister of Health be given powers to propose regulation if after two years there had been no significant progress in achieving its objective [47]. Subsequently, the Government also actively supported self regulatory policy in their response to the Obesity and Diabetes Inquiry report [48].

The minority Green Party were strongly supportive of the policymakers' and NGOs' pro-regulatory position:
"It is crucial that we protect our children from commercial pressures on them to eat unhealthy food, that will undermine their health, learning and well being " [49].

However, following a change to a centre-right government in 2008 the Public Health Bill did not proceed in any form. Subsequently, Minister of Health, Tony Ryall, expressed commitment to continuing to support industry self 
regulation in his 2010 statement to advertising, communication and food industry representatives:

"Working with industry and food
manufacturers constructively is an approach
Government supports and we want to see more
examples of the achievements in this area,"
[50].

The outcome is New Zealand's continuation of an industry controlled self-regulatory framework for broadcast media only. There are no policy controls on other media. The industry-funded Advertising Standards Authority administers a complaints based and voluntary Children's Code for Advertising Food [51]. This code refers to the NZ Television Broadcasters Council's voluntary social responsibility code $[51,52]$ which restricts advertising in school-age children's television programme times to 10 minutes per hour, morning and afternoon, ending no later than $6.00 \mathrm{pm}$. Advertisements for foods and beverages are subject to a classification as every day, sometimes or occasional foods, along with an expert nutrient profiling as being either healthy or unhealthy. Based on the outcome of this scrutiny a food or beverage advertisement is given permission to be screened. Whilst the NZ Advertising Standards Authority makes several references to the United Nation's Convention on the Rights of the Child and the freedoms of childhood, the Authority chooses to impinge on one of these freedoms by defining the age of a child as under 14, four years younger than the United Nations defining age of under 18 . With a narrow definition of children's viewing times, relying on complaints post screening, a delay in complaints being considered and weak penalties, there is no effective control over food and beverage advertisements after $6 \mathrm{pm}$ when a large number of children are watching television. Analysis of a 2008 complaint to the NZ Advertising Standards Authority concluded that, for public health issues, self regulatory mechanisms offer questionable levels of protection [8].

\section{DISCUSSION}

Our study found three groups actively attempting to influence government policy on television advertising to children. Advocacy by the food industry was tightly coordinated and consistent in lobbying for industry self regulation. NGO and academic coalition groups did not appear to coordinate their advocacy in the media. Nevertheless, their arguments for government regulation were consistent, cogent and heavily evidence based. Government policymakers generally had a low profile, until a policy window appeared when they swiftly revealed their preference for government intervention. Overall, it was difficult to determine the nature and extent of covert advocacy, particularly by the food industry, which is well known for such tactics in other countries [18, 53-55]. A request under the Official Information Act produced internal government documents. However, it was not possible to definitively link food industry advocacy to government position as six members of the food industry declined an interview request. Our position as University health researchers probably made it difficult to uncover any instances of back room influence. Industry groups are likely to only share this information with trusted colleagues. We did gain insights into the positions and activities of all three groups through our qualitative interviews. Although the food industry did not participate in interviews, the Advertising Standards Authority (ASA) willingly discussed their views and the position of their industry supporters. The ASA interviews together with the Select Committee submissions provided a rare window on the position of different industry sectors and some insights into their approach.

\section{Vested Interests and Uncertainty}

The vested interests construct is also useful for explaining the varying involvement and level of activity of each of the advocacy groups. Interest groups are identifiable by political scientists when they form around a shared view of the preferred policy outcome and coordinate their advocacy activities. The level of organisation depends on how high the stakes are for the group, their access to resources and their ability to organise themselves [22]. In this study the food industry displayed all the characteristics and motivations of an organised, well-resourced vested interest group working on a high stakes issue. As a group whose role in economic growth is recognised by government, the food industry are in a strong bargaining position [56]. The establishment of the Food Industry Group (FIG) enabled coordinated and consistent advocacy. By contrast, the NGO groups operated as a number of coalitions who were informally linked by having a high level of members in common. Although these cause related groups are highly regarded by the wider community their level of government influence was low compared to the food industry. Industry have numerous points of interaction with government as providers of tax revenues, as major employers, through international linkages and as holders of specialised knowledge [56]. This asymmetry of influence gives the private sector considerable power in public health policy making.

Nestle [57] and others have reported the behaviour and considerable influence of the food industry on food marketing to children policy. Nestlé's work focuses on the United States where lobbying is embedded in the political system and the food industry expends considerable effort to lobby, conduct PR campaigns, make financial contributions, and develop partnerships and alliances. Our study was conducted in an open system of policymaking, similar to the United Kingdom (UK) where paid lobbying is illegal. Our findings revealed similar direct and indirect lobbying tactics to those reported by Miller et al. [55] in their examination of lobbying by the UK food and alcohol industry: the creation of scientific uncertainty; the use of the media to influence popular and elite opinion; and the development of industry government partnerships. The influence strategies used by the NZ food industry were mostly conducted by one coordinating organisation, FIG, which was solely established for this purpose. Their public relations activities, seminars, media statements and release of website resources were undertaken in a carefully timed high profile publicity strategy. By questioning the evidence base for obesity interventions in their submission to the Health Select Committee Inquiry, industry groups sought to reduce the authority of the academic submitters who argued there was sufficient evidence for action. The industry - government partnership agreement, the Food Industry Accord, was a masterful outcome as industry undertook to share 
responsibility with government for addressing the obesity problem. This agreement positioned industry as a major contributor to the solution of the obesity problem, shifting the attention from the causes of obesity, whilst adroitly not committing themselves to any measurable goals. The involvement of unelected partners in the delivery of policy is increasingly a feature of social and health policy, in the UK, continental Europe and globally. Such partnerships are recognised for eroding barriers between government and the private sector, which creates difficulty for governments to pursue policy for public health reasons where policies raise conflicts of interest [55].

The creation of scientific uncertainty is a highly successful food industry and corporate tactic. Scientific uncertainty is the strategy of questioning the underlying science in order to prevent regulation [58]. In this study the food industry submissions to government select committees questioned the underlying science on the causes and prevention of obesity, thus creating uncertainty around the optimal evidence based policy tool. Michaels and Monforton highlighted the same tactic by aspirin manufacturers and the tobacco industry seeking to delay the requirement for specific warning labels in the 1980 s, observing that the tactic is now so commonly used in the United States that is unusual for the science behind a proposed public health or environmental regulation not to be challenged by an industry group [58].

\section{Powerful Advocacy}

The food industry's overarching goal was the retention of the industry self-regulatory policy framework. By developing a partnership with government to solve the obesity problem, industry presented themselves as a trusted, organised group who is sharing responsibility. Secondly, by indicating that their members needed to change current approaches to manufacture and promotion, the food industry acknowledged that they did not have a quick fix and so could not be held accountable for short-term outcomes. This playing for time was directly opposite to the NGO groups' advocacy goals, which centred on immediate imposition of government regulation banning all food marketing to children. The NGO groups with their strong links to academia adopted the position of the critic and conscience of society arguing that responsibility for effective action lies firmly with central Government.

Internationally the food industry is renowned for using powerful vested interest group advocacy tactics $[10,55,59$ 62]. As Lobstein observes " a primary aim of industry is to capture the regulatory process through lobbying, party funding and through their membership of the very regulatory bodies that should be holding them to account" [63].

Both industry and NGO groups used evidence to support their positions. The NGO groups frequently quoted international research published in academic journals. This study concurred with a major European study [12] in showing that although industry groups also claimed their arguments were evidence based, this evidence was either hard to locate or did not meet stringent academic publication criteria. This fact did not dampen the 'supported by evidence' rhetoric used by industry, which effectively diminished the power of the NGO groups' evidence based arguments to all audiences except the scientifically educated. The continued dominance of the NZ food industry in influencing government policy on television food advertising to children by virtue of their dominant structural position across government and within regulatory structures, and effective advocacy strategies, has enabled the continuation of a policy that serves their interests at the expense of public health.

The vested interests construct is also useful for explaining the influence such powerful groups have over health policy. Vested interests are organised groups who define their domain and act to maintain the survival and advancement of their organisation within that domain [22]. Groups have varying levels of organisation depending on the issue at stake and the resources at their disposal. Economic interest groups often act covertly to frame policy issues and their resolution. The policy debates on global warming, tobacco control and food fortification reflect the role of powerful interest groups promulgating evidence they have commissioned in their framing of issues and solutions. It is well recognised that these powerful structural interest groups play a significant role in agenda setting and policy shaping debates [23].

A structural interest's view also explains the medical profession's dominance in health through the prevailing concepts of health serving their interests. Defining health in terms of illness or disease legitimises the medical profession's focus on treating individuals. Similarly, the food industry framing childhood obesity as an issue of parental responsibility, personal autonomy and education legitimises their focus on preserving choice through market self-regulation. Dominant groups, such as the food industry frequently have their interests served by existing social, political and economic interests. For example, at a global level, transnational food companies have developed international food trade and sourcing arrangements, influenced the restructuring of food retailing with the growth in supermarkets and used global food advertising and promotions to influence consumption habits and create demand. Organised interest groups such as NGOs can challenge a dominant position by arguing for an alternative position. In this study the $\mathrm{NGO} /$ academic interest group presented strong arguments that food advertising to children is a controllable environmental contributor to childhood obesity. However, these arguments proved to be surface activity that did not threaten the deeply entrenched position of the dominant food industry. Within the health sector, this level of impact by a less dominant group is a familiar pattern $[23,64,65]$.

\section{The Implications for Obesity}

We found that the policy around television food advertising to children is a case where a powerful vested interest group has maintained the status quo policy to protect their own interests. Through the use of well-organised advocacy strategies leveraged from a structurally dominant position, the food industry group have effectively determined current Government policy. As the government also bears the cost of obesity treatment, industry could be seen as forcing government to act against its own best interests. 
In contrast, our case study supports the international call for new policy mechanisms to address the rise in obesity [16, $24,66,67]$, to avoid a continuation of outcomes favouring the interests of the powerful food industry. These emerging meta policy approaches reframe obesity as an issue with complex, interrelated determinants requiring coordinated inter-sectoral action [16]. When obesity is viewed as having social, technical and ideological drivers, policy solutions move from diet and physical activity only approaches to include social, economic and cultural dimensions. This twenty first century approach to public health policy replaces the Victorian approach of reshaping the physical environment by installing drains and supplying safe drinking water. Different attributions of causes imply different policy solutions. Our findings support those of others [24, 67] in identifying that the considerable influence of vested interest groups requires more than new ideas about causes and solutions to reduce their influence and dominant position. The policy making process itself requires change. The new obesity meta policy frameworks acknowledge this need in recommending collaborative processes moderated by government agents $[24,68]$. Policy makers are directed to use a multi-sectorial approach to obesity prevention, involving industry groups, but not allowing them to dominate public health policy development. Such approaches are rare internationally and certainly, as our study found, not evident in New Zealand.

The powerful food industry has been criticised for being slow to change its behaviour in spite of being requested to do so by the WHO [68]. Machiavelli is often quoted as observing that the shaping of policy outcomes by vested interests is not a new phenomena [69], nor is it restricted to food and obesity issues in the twenty first century [9]. However, in the twenty first century it is increasingly unacceptable for powerful lobby groups to use reductionist tactics to frame global disease epidemics as personal choice issues in single countries $[3,9,63,70]$.

Advocates for international policy action on the obesity epidemic argue that the tipping point has been reached as a rapidly growing percentage of the child population in developed countries are now being classified as overweight or obese [16]. A "tipping point" [71] is the concept in epidemiology that small changes will have little or no effect on a system until a critical mass is reached. Then a further small change "tips" the system and a large effect is observed. The intensifying advocacy for effective policy creates unrelenting pressures on vested interests to tip from their entrenched policy positions and engage in collaborative, transparent processes. We found some evidence of increased engagement. However, firm indicators of changed positions were elusive.

Such approaches to policymaking require strong government leadership. However, caution is warranted. From alcohol policy development, lessons can be learnt about the pros and cons of partnership approaches. Relationships between the alcohol industry and the health sector have been labelled 'poisonous partnerships' because of the power imbalance in favour of industry [9]. The role of government agencies working with industry also requires scrutiny as both groups derive benefit from consumption in the form of taxes or profit. Consequently, there is evidence of industry and government agreeing to pursue harm reduction measures that do not directly address the real drivers of consumption, These actions include improving the environments in which consumption takes place, such as host responsibility in bars or smoke-free social spaces. We agree with Adams et al., that balanced government-centered models of managed interaction are ideal, but these do require long term government resolve to sustain [9]. The current appetite for partnership arrangements between industry, government and the health sector offers opportunity for further refinement of such collaborative arrangements and study.

\section{CONCLUSION}

The case of food marketing to children in New Zealand provides compelling evidence that vested interests have worked to maintain an outdated policy response to a twenty first century problem, now classified as an obesity epidemic. This situation is not unique. Internationally a tipping point needed to change the policy frame around obesity prevention, from individual choice and autonomy to a frame that acknowledges multiple causes and solutions. The food industry are key players in any solution, they have significant resources and are skilled at interacting persuasively with consumers to promote consumption. The industry is also adept in employing a range of tactics to maintain a policy position around food advertising to children to protect its current vested interests. The development of multi-sector policy would involve all parties reframing the issues and the development of new targets. Radical suggestions such as rewarding the sales volume of healthy food, regulation for marketing activity promoting healthy food, and other creative, incentivised strategies require collaborative discussions across sectors.

The role of government as policymakers needs to increase to meaningfully address the WHO and other groups' deep concerns about rising rates of childhood obesity [66, 72]. Only government as the legislative policymaker has this prerogative. In the twenty first century an inter-sectoral policy solution is needed to address childhood obesity. A shift by industry from their entrenched policy position is also required, as is a longterm commitment to working collaboratively with other policy stakeholders. Our work indicates that in a small country, with relatively few key policy stakeholders, collaborations between industry and government are emerging, although the NGO groups saw these arrangements as an assertion of vested interests. Both the costs and long-term benefits will be apparent in the health, agriculture, education, environment, transport and economic sectors, although not equally borne, which explains some of the structural resistance to change. Despite the apparent barriers the recent moves to coordinate policy development on climate change offers a source of optimism that obesity prevention policy can be reframed. As a small politically flexible country, New Zealand does have the potential to lead the world in using collaborative twenty first century policy development processes to address the rising rates of childhood obesity.

\section{REFERENCES}

[1] Rigby NJ, Kumanyika S, James WPT. Confronting the epidemic: the need for global solutions. J Public Health Policy 2004; 25(3/4): 418-34. 
[2] WHO. Global strategy on diet, physical activity and health, childhood overweight and obesity. World Health Organisation; 2011 [cited 20112 February]; Available from: http://www.who. int/dietphysicalactivity/childhood/en/index.html.

[3] Nestle M. Food marketing and childhood obesity - a matter of policy. New England J Med 2006; 354(24): 2527 -9.

[4] Wootan MG. Guidelines for responsible food marketing to children. Washington DC: center for science in the public interest 2005.

[5] Batada A, Seitz MD, Wootan MG, Story M. Nine out of 10 food advertisements shown during Saturday morning children's television programming are for foods high in fat, sodium, or added sugars, or low in nutrients. J Am Diet Assoc 2008; 108(4): 673-8.

[6] Wilson N, Signal L, Nicholls S, Thomson G. Marketing fat and sugar to children on New Zealand television. Prev Med 2006; 42(2): 96-101.

[7] Room R. British livers and British alcohol policy. The Lancet 2006; 367(9504): 10.

[8] Hoek J, King B. Food advertising and self-regulation: a view from the trenches. Aust N Z J Public Health 2008; 32(3): 261-5.

[9] Adams PJ, Buetow S, Rossen F. Vested interests in addiction research and policy poisonous partnerships: health sector buy-in to arrangements with government and addictive consumption industries. Addiction 2010; 105(4): 585-90

[10] Story M, French S. Food Advertising and marketing directed at children and adolescents in the US. Int $\mathbf{J}$ Behav Nutr Phys Act 2004; 1(1): 3 .

[11] Institute of Medicine US. Committee on food marketing and the diets of children and youth: threat or opportunity. Washington: The National Academies Press 2006.

[12] Matthews AE. Children and obesity: a pan-European project examining the role of food marketing. Eur J Public Health 2008; 18(1): 7-11.

[13] Rideout VJ FUG, Roberts DF Generation M2: media in the lives of 8-18 year-olds 2010; Available from: http://www.kff.org/entmedia/ upload/8010.pdf.

[14] Livingstone S, Helsper EJ. Does advertising literacy mediate the effects of advertising on children? A critical examination of two linked research literatures in relation to obesity and food choice. $\mathrm{J}$ Commun 2006; 56(3): 560-84.

[15] Hastings G, Stead M, McDermott L, et al. Review of research on the effects of food promotion to children. Food Standards Agency UK 2003.

[16] Lang T, Rayner G. Overcoming policy cacophony on obesity: an ecological public health framework for policymakers. Obes Rev 2007; 8: 165-81.

[17] Adams J, Hennessy-Priest K, Ingimarsdóttir S, Sheeshka J, Østbye T, White M. Food advertising during children's television in Canada and the UK. Arch Dis Child 2009; 94(9): 658-62.

[18] Caraher M, Landon J, Dalmeny K. Television advertising and children: lessons from policy development. Public Health Nutr 2006; 9(05): 596-605.

[19] Wilde P. Self-regulation and the response to concerns about food and beverage marketing to children in the United States. Nutr Rev 2009; 67(3): 155-66.

[20] Lewis JM. Being around and knowing the players: networks of influence in health policy. Soc Sci Med 2006; 62(9): 2125.

[21] Quanstrum KH, Hayward RA. Lessons from the mammography wars. NEJM 2010; 363(11): 1076-9.

[22] deLeeuw E. Health Policy, epidemiology and power: the interest web. Health Promot Int 1993; 8(1): 49- 52.

[23] Palmer GR, Short SD. Health care \& public policy: an Australian analysis 2nd ed. South Melbourne Macmillan Education Australia; 1994.

[24] Swinburn B, Gill T, Kumanyika S. Obesity prevention: a proposed framework for translating evidence into action. Obes Rev 2005; 6(1): 23-33.

[25] Crampton P, Hoek J, Beaglehole R. Leadership for health: developing a canny nanny state. N Z Med J 2011; 124(1329): 6672 .

[26] Yin RK. Case study research design and methods. Fourth ed. California: Sage Inc 2009

[27] Pope C, Mays N, Popay J. Synthesising qualitative and quantitative health evidence. England: Open University Press 2007.

[28] Irwin J. The Food industry group[fig] 2nd annual report to the Minister of Health 2006.
[29] Food Industry G. N.Z. Food Industry. Accord, The Health of Our Nation 2004 [cited 201119 January]; Available from: http://www .nztbc.co.nz/images/food_ind_accord.pdf.

[30] Rationale for FIG success: Food Industry Group 2008.

[31] White J. The health select committee inquiry into obesity and type two diabetes in New Zealand: an initial analysis of submissions. Wellington: Fight the Obesity Epidemic New Zealand Incorporated 2007.

[32] New Zealand food and grocery council in submission to obesity and type 2 diabetes inquiry health select committe, New Zealand Government 2006

[33] White J. The health select committee inquiry into obesity and type two diabetes in New Zealand: an initial analysis of submissions Section 3.5 evidence and the need for action. Wellington: fight the obesity epidemic New Zealand Incorporated 2007.

[34] New Zealand Food Industry Group Inc. 2011 [cited 201120 January]; Homepage]. Available from: http://www.fig.org.nz/.

[35] Kedgley S. Inquiry into obesity and type 2 diabetes in New Zealand report of the health committee: NZ House of Representatives 2007.

[36] Tait M. McDonalds argues against health bill regulation. New Zealand Herald 2008.

[37] Submission of the New Zealand retailers association to the health select committee in respect of the public health bill 2008 [cited 201119 January]; Available from: http:/www.retail.org.nz/down loads/Public Health Bill.pdf

[38] Obesity and type 2 diabetes inquiry. A submission prepared by the National Heart Foundation of New Zealand 2006 [cited 201120 January]; Available from: http:/www.heartfoundation.org.nz/files/ Submission 210406c.pdf

[39] Oliver P. Tough food controls in anti-obesity bill. New Zealand Herald 2008

[40] Scragg R, Quigely R, Taylor R. Does watching TV contribute to increased body weight and obesity in children ? Wellington: agencies for nutrition action 2006

[41] Obesity action coalition. Would you like lies with that? 2007.

[42] Phoenix research. Survey of public opinions about advertising food to children: understanding attitudes in New Zealand. Auckland: Peak Group 2007.

[43] Inquiry into obesity and type 2 diabetes NZ Medical Association submission health select committee, New Zealand Government 2006.

[44] Hodson P. Address to food industry group seminar. Food industry group seminar; Auckland 2006.

[45] Toomath R. Policy stakeholder interview. In: Field P, Ed. Wellington 2005.

[46] Marketing of food to children: background information and policy options. Wellington: Ministry of Health 2007.

[47] Health Committee. Public health bill, government bill As reported from the Health Committee. Wellington: house of representatives 2008.

[48] Government response to the Inquiry into Obesity and Type 2 Diabetes presented to the House of Representatives in accordance with standing order 253 (J.1): New Zealand Parliament 2007.

[49] Kedgely S. Ad industry behaving like King Canute. Green party of Aotearoa New Zealand; 2008 [cited 201121 January]; Press Release]. Available from: http://www.greens.org.nz/pressreleases/ad-industry-behaving-king-canute.

[50] Ryall T. Meeting with communication and advertsing industry representatives and food industry CEOs. Communication agencies association NZ [ CAANZ] Ripple Newsletter 2010.

[51] New Zealand Advertising Standards Authority. New Zealand Advertising Standards Authority children's code for advertising food 2010. [cited 201120 September]; Available from: http://www.asa.co.nz/code_children_food.php.

[52] ThinkTV. Getting it right for children. [cited 201120 September]; Available from: http://www.thinktv.co.nz/thinktv/standards-andregulations/children-an-tv/.

[53] Nestle M. Influencing government food lobbies and lobbyists. Food politics: how the food industry influences nutrition and health 2002; p. 95-110.

[54] Lawrence M. Policy and politics. In: Lawrence M, Worsley T, Eds. Public Health Nutrition from principles to practice: Allen \& Unwin 2007; p. 450-76.

[55] Miller D, Harkins C. Corporate strategy, corporate capture: food and alcohol industry lobbying and public health. Critical social Policy 2010; 30(4): 564-89. 
[56] Buse K, Mays N, Walt G. Making health policy. Black N, Raine R, ed.: Open University Press 2005.

[57] Nestle M. The politics of food choice. Food politics: how the food industry influences nutrition and health 2002; p. 358-74.

[58] Michaels D, Monforton C. Manufacturing uncertainty: contested science and the protection of the public's health and environment. Am J Public Health. 2005; 95: S39-S48.

[59] Lang T. Food, the law and public health: Three models of the relationship. Public Health. 2006; 120(Suppl 1): 30.

[60] Hoek J, Maubach N. Self-Regulation, marketing communications and childhood obesity: a critical review from New Zealand Loyola of Los Angeles law review. 2005; 39(1): 139-68.

[61] Nestle M. Food Politics. University of California Press 2002; p. 95110.

[62] Haslam DW, James WPT. Obesity. The Lancet 2005; 366(9492): 1197.

[63] Lobstein T. Commentary on "food, the law and public health". Public Health 2006; 120(Suppl 1): 40.

[64] Lewis JM. Health policy and politics: networks, ideas and power. Melbourne: IP Communications 2005.
[65] Ham C. Power in health services. In: Ham C, Ed. Health Policy in Britain: The politics and organisation of the national health service: Macmillan Press 1985; p. 180-91.

[66] World Health Organisation Secretariat. Prevention and control of noncommunicable diseases: implementation of the global strategy. Geneva: World Health Organisation 2010. Report No.: A63/12.

[67] Swinburn B, Sacks G, Lobstein T, Rigby N, Baur L, Brownell K, et $a l$. Sydney Principles' for reducing the commercial promotion of foods and beverages to children. Public Health Nutr 2008; 11(9): 881.

[68] WHO. Population-based preventions strategies for childhood obesity report of the WHO. Geneva: World Health Organisation 2010.

[69] Harris P, Lock A. Machiavellian marketing: the development of corporate lobbying in the UK. J Mark Manage 1996; 12(4): 313-28.

[70] Swinburn BA. Commentary: closing the disparity gaps in obesity. Int J Epidemiol 2009; 38(2): 509-11.

[71] Gladwell M. The tipping point :how little things can make a big difference. 1st ed. Boston: Little Brown 2000.

[72] Beaglehole R, Bonita R, Horton R, Adams O, McKee M. Public health in the new era: improving health through collective action. The Lancet 2004; 363(9426): 2084.

(C) Field and Gauld; Licensee Bentham Open.

This is an open access article licensed under the terms of the Creative Commons Attribution Non-Commercial License (http://creativecommons.org/licenses/by$\mathrm{nc} / 3.0 / /$ / which permits unrestricted, non-commercial use, distribution and reproduction in any medium, provided the work is properly cited. 